\title{
Hypermanganesaemia in patients receiving home parenteral nutrition: a longitudinal study over $1000 \mathrm{~d}$
}

\author{
N. S. Hallum ${ }^{1}$, D. C. Mcmillan ${ }^{1}$, D. S. J. O’Reilly' ${ }^{2}$ J. P. Baxter ${ }^{3}$ and R. F. Mckee ${ }^{1}$ \\ ${ }^{1}$ Department of Surgery and ${ }^{2}$ Department of Biochemistry, Glasgow Royal Infirmary, Glasgow G31 2ER, UK \\ and ${ }^{3}$ Scottish Home Parenteral Nutrition Managed Clinical Network, Ninewells Hospital and Medical School, \\ Dundee DDI 9SY, UK
}

Patients receiving home parenteral nutrition (HPN) are often found to be hypermanganesaemic ${ }^{(1)}$. The mechanism of how HPN leads to hypermanganesaemia is poorly understood but manganese $(\mathrm{Mn})$ dose, liver function ${ }^{(2,3)}$ and inflammation ${ }^{(1)}$ may be relevant. A group of twelve patients was studied for 1000 days after starting HPN and their whole blood Mn levels at 100, 500 and 1000 days measured, together with their Mn dosing regimen over the same period. Liver function (represented by alkaline phosphatase), ferritin and C-reactive protein (CRP) were also measured. Patient dosing regimens were used to calculate cumulative Mn doses for each patient.

The Managed Clinical Network collects prospective data on all patients receiving HPN in Scotland. Trace elements are measured centrally in one laboratory. The data for patients attending one tertiary referral centre was examined.

With twelve patients and three time periods, a total of thirty-six Mn levels were possible. Four levels were not measured. Eleven of the twelve (92\%) patients recorded abnormally high Mn levels at least once, five patients at all three time points. Twenty-five of thirty-two $(78 \%) \mathrm{Mn}$ levels were abnormal and thirteen of these were greater than twice normal levels. Individually, stopping or reducing the dose of Mn caused a drop in levels towards normal. However, for the group as a whole there was no significant difference in Mn level $(P<0.236)$ over the time periods. Neither ferritin nor CRP varied significantly over the period but alkaline phosphatase was significantly different $(P<0.013)$.

Hypermanganesaemia is common amongst patients receiving HPN and responds to a decrease in dose or omission of the supplement. However, Mn levels did not differ overall throughout the $1000 \mathrm{~d}$. The individual changes in blood Mn cannot be explained by either liver dysfunction or inflammatory response, as there was no significant correlation with markers of either. It is likely that complex confounding factors influence whole blood Mn levels. Further work is needed to elucidate these factors.

1. Reimund JM, Dietemann JL, Warter JM et al. (2000) Clin Nutr 19, 343-348.

2. Reynolds N, Blumsohn A, Baxter JP, Houston G, Pennington CR (1998) Clin Nutr 17 (5), 227-230.

3. Wardle CA, Forbes A, Roberts N, Jawhari AV, Shenkin A. (1999) JPEN 23 (6), 350-355. 